NASA/TM-2011-216994

\title{
Enabling Long-Duration Lunar Equatorial Operations With Thermal Wadi Infrastructure
}

Heather L. Jones and John P. Thornton

Carnegie Mellon University, Pittsburgh, Pennsylvania

Ramaswamy Balasubramaniam

National Center for Space Exploration Research, Cleveland, Ohio

Suleyman A. Gokoglu and Kurt R. Sacksteder

Glenn Research Center, Cleveland, Ohio

William L. Whittaker

Carnegie Mellon University, Pittsburgh, Pennsylvania 


\section{NASA STI Program . . . in Profile}

Since its founding, NASA has been dedicated to the advancement of aeronautics and space science. The NASA Scientific and Technical Information (STI) program plays a key part in helping NASA maintain this important role.

The NASA STI Program operates under the auspices of the Agency Chief Information Officer. It collects, organizes, provides for archiving, and disseminates NASA's STI. The NASA STI program provides access to the NASA Aeronautics and Space Database and its public interface, the NASA Technical Reports Server, thus providing one of the largest collections of aeronautical and space science STI in the world. Results are published in both non-NASA channels and by NASA in the NASA STI Report Series, which includes the following report types:

- TECHNICAL PUBLICATION. Reports of completed research or a major significant phase of research that present the results of NASA programs and include extensive data or theoretical analysis. Includes compilations of significant scientific and technical data and information deemed to be of continuing reference value. NASA counterpart of peer-reviewed formal professional papers but has less stringent limitations on manuscript length and extent of graphic presentations.

- TECHNICAL MEMORANDUM. Scientific and technical findings that are preliminary or of specialized interest, e.g., quick release reports, working papers, and bibliographies that contain minimal annotation. Does not contain extensive analysis.

- CONTRACTOR REPORT. Scientific and technical findings by NASA-sponsored contractors and grantees.
- CONFERENCE PUBLICATION. Collected papers from scientific and technical conferences, symposia, seminars, or other meetings sponsored or cosponsored by NASA.

- SPECIAL PUBLICATION. Scientific, technical, or historical information from NASA programs, projects, and missions, often concerned with subjects having substantial public interest.

- TECHNICAL TRANSLATION. Englishlanguage translations of foreign scientific and technical material pertinent to NASA's mission.

Specialized services also include creating custom thesauri, building customized databases, organizing and publishing research results.

For more information about the NASA STI program, see the following:

- Access the NASA STI program home page at http://www.sti.nasa.gov

- E-mail your question via the Internet to help@ sti.nasa.gov

- Fax your question to the NASA STI Help Desk at $443-757-5803$

- Telephone the NASA STI Help Desk at 443-757-5802

- Write to: NASA Center for AeroSpace Information (CASI) 7115 Standard Drive Hanover, MD 21076-1320 
NASA/TM-2011-216994

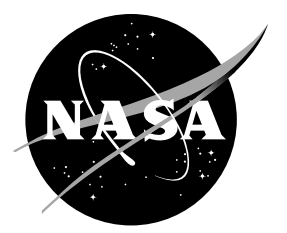

\section{Enabling Long-Duration Lunar Equatorial Operations With Thermal Wadi Infrastructure}

Heather L. Jones and John P. Thornton

Carnegie Mellon University, Pittsburgh, Pennsylvania

Ramaswamy Balasubramaniam

National Center for Space Exploration Research, Cleveland, Ohio

Suleyman A. Gokoglu and Kurt R. Sacksteder

Glenn Research Center, Cleveland, Ohio

William L. Whittaker

Carnegie Mellon University, Pittsburgh, Pennsylvania

Prepared for the

49th Aerospace Sciences Meeting

sponsored by the American Institute of Aeronautics and Astronautics

Orlando, Florida, January 4-7, 2011

National Aeronautics and

Space Administration

Glenn Research Center

Cleveland, Ohio 44135 
Trade names and trademarks are used in this report for identification only. Their usage does not constitute an official endorsement, either expressed or implied, by the National Aeronautics and Space Administration.

Level of Review: This material has been technically reviewed by technical management.

Available from

NASA Center for Aerospace Information 7115 Standard Drive

Hanover, MD 21076-1320
National Technical Information Service 5301 Shawnee Road Alexandria, VA 22312

Available electronically at http://www.sti.nasa.gov 


\title{
Enabling Long-Duration Lunar Equatorial Operations With Thermal Wadi Infrastructure
}

\author{
Heather L. Jones and John P. Thornton \\ Carnegie Mellon University \\ Pittsburgh, Pennsylvania 15213 \\ Ramaswamy Balasubramaniam \\ National Center for Space Exploration Research \\ Cleveland, Ohio 44135 \\ Suleyman A. Gokoglu and Kurt R. Sacksteder \\ National Aeronautics and Space Administration \\ Glenn Research Center \\ Cleveland, Ohio 44135 \\ William L. Whittaker \\ Carnegie Mellon University \\ Pittsburgh, Pennsylvania 15213
}

\begin{abstract}
Long duration missions on the Moon's equator must survive lunar nights. With $350 \mathrm{hr}$ of cryogenic temperatures, lunar nights present a challenge to robotic survival. Insulation is imperfect, so it is not possible to passively contain enough heat to stay warm through the night. Components that enable mobility, environmental sensing and solar power generation must be exposed, and they leak heat. Small, lightweight rovers cannot store enough energy to warm components throughout the night without some external source of heat or power. Thermal wadis, however, can act as external heat sources to keep robots warm through the lunar night. Electrical power can also be provided to rovers during the night from batteries stored in the ground beside wadis. Buried batteries can be warmed by the wadi's heat. Results from analysis of the interaction between a rover and a wadi are presented. A detailed three-dimensional (3D) thermal model and an easily configurable two-dimensional (2D) thermal model are used for analysis.
\end{abstract}

\section{Nomenclature}

$\begin{array}{ll}A_{r} & \text { area of rover } \\ A_{s} & \text { area of shield } \\ T_{r} & \text { temperature of rover } \\ T_{s} & \text { temperature of shield } \\ \varepsilon_{r} & \text { emissivity of rover } \\ \varepsilon_{\mathrm{S}} & \text { emissivity of shield } \\ C_{p} & \text { battery specific heat } \\ \Delta T & \text { change in battery temperature } \\ M & \text { battery mass } \\ P & \text { battery heating rate } \\ t & \text { time }\end{array}$




\section{Introduction}

Recent discoveries from lunar orbiters and impactors are motivating a return to the lunar surface. The Moon's materials and proximity also make it a prime location for exploiting resources. It costs considerable fuel mass and mission complexity to soft-land a robotic mission on the lunar surface, so it makes sense to maximize the surface operations phase of landed missions. Mars exploration rovers have done well, far exceeding their nominal 90 day mission with over 6 years of operation. Unfortunately, because the Moon lacks an atmosphere and is much nearer to the Sun than Mars, rovers on the Moon face much more difficult thermal extremes than those on Mars.

Rovers near the lunar poles could circumnavigate the globe on a route of perpetual Sun (Refs. 1 and 2), but rovers that venture to the equatorial regions must tackle the thermal challenges of the full day/night cycle. During the lunar day, rovers must shed heat efficiently to avoid overheating components as the lunar surface reaches nearly $400 \mathrm{~K}$ (Ref. 3). During the lunar night, surface temperatures drop below $100 \mathrm{~K}$, well beyond the operating temperatures of rover components. Because the lunar night lasts 14 Earth days, a small, lightweight rover cannot carry enough battery mass to heat itself throughout the night (Ref. 1). The Russian Lunokhod rovers met the lunar night challenge with radioisotope thermal generators (Ref. 4), but availability of radioactive materials for this purpose is very limited, and programmatic hurdles make such materials unrealistic for non-governmental entities.

A wadi is a thermal mass that can act as an external heat source to keep a rover within operating temperatures throughout the lunar night. For the purposes of this study, the minimum operating temperature of electronics is assumed to be $243 \mathrm{~K}\left(-30^{\circ} \mathrm{C}\right) .{ }^{1}$ The baseline wadi configuration includes a heat-loss limiting shield that covers the wadi and rover during the night. Wadi effectiveness is highly dependent on the presence of this shield and its properties. Results from three-dimensional (3D) and two-dimensional (2D) thermal models with varying shield properties are presented.

In addition to the thermal interaction, a wadi could provide the rover with other amenities. A concept for a wadi with electrical power is discussed. The scenario of using wadi power to heat a rover to compensate for a non-optimal shield configuration is also examined.

\section{Analysis of Rover and Wadi}

Previous work estimated the effect of heat power provided to a rover on wadi temperature by assuming a constant-power heat loss throughout the night (Ref. 5). That analysis showed that a wadi can remain warm through the night when providing $25 \mathrm{~W} / \mathrm{m}^{2}$ of constant heat flux to a rover. By modeling rover geometry, analysis herein extends those results with a more realistic time-varying model of heat power drawn by a rover. More importantly, this analysis also examines how the heat from a wadi affects a rover.

To insure that the rover in this work is realistic for the Moon, we use a detailed 3D thermal model of a rover designed at Carnegie Mellon. This model has been analyzed under equatorial lunar-day thermal environments and shown to perform well. A 3D wadi model is added for this study. The detailed 3D model does have the disadvantage of being very design-specific and not easy to modify for other rover configurations. Previous analysis of wadi's has shown that 1D, 2D, and 3D models produce similar results (Ref. 6), so we compare the results of the detailed 3D model with those of a simplified 2D model of rover and wadi. Three cases are examined with each model (1) a rover on a wadi with no shield, (2) a rover on a wadi with a shield, and (3) a rover on a wadi with a low emissivity shield.

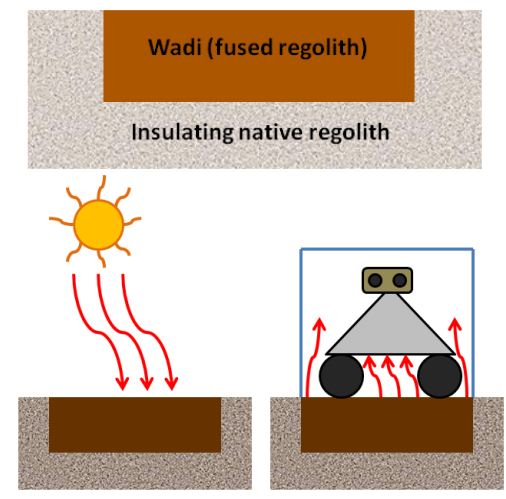

Figure 1.-Basic wadi concept: a thermal mass is created by fusing regolith (top). Wadi is heated by the Sun during the day (lower left) and provides heat to a rover during the night (lower right). A heat loss limiting shield reduces the radiation of heat to free space.

\footnotetext{
${ }^{1}$ The minimum operating temperature of the A123 Systems ANR26650M1A lithium iron phosphate battery cell is $-30{ }^{\circ} \mathrm{C}$, according to the product datasheet (http://www.a123systems.com/cms/product/pdf/1/_ANR26650M1A.pdf). The authors acknowledge that many components have minimum operating temperatures above $-30^{\circ} \mathrm{C}$, but we believe it is reasonable to select components that work to this minimum. The analysis presented here does not incorporate the heat generated by operating rover components. It is expected that component temperatures would increase if self-generated heat were included, so this analysis shows a worst case for a given wadi configuration.
} 


\section{A. Rover Configuration}

The rover used in this analysis is an asymmetric solarpowered design which achieves passive thermal regulation for the hot lunar equatorial day. ${ }^{2}$ The two main goals of the design are to minimize heat flow in and to maximize heat flow out through the radiator.

Since regolith temperatures on the lunar equator reach nearly $400 \mathrm{~K}$, sensitive rover components must be insulated from the ground as well as from the incident sun. The $55^{\circ}$ angle of the static solar panels is optimized to balance surface area, incident sun angle and panel heating from regolith-reflected radiation. The interior surface of the solar array structure is lined with multi-layer insulation (MLI) to reduce radiation from the solar panels to the rover internal components. Delicate MLI mounted on the underside of the chassis may be damaged when traversing rough terrain, so MLI is mounted on the inside of the chassis floor. Isolation cones, constructed of Ultem, minimize heat flow from the chassis to internal rover components while still providing a strong structural connection.

The asymmetric rover turns to point the solar panels to the Sun while pointing the radiator away from the Sun to dissipate heat more efficiently. The $30^{\circ}$ angle on the radiator is a function of optimization to minimize heat absorption from incident sun and regolith-reflected radiation. Heat generating components inside the rover are either mounted directly to the radiator or connected to the radiator through high-conductivity thermal pathways. The main computer and several other avionics components are attached to the underside of the radiator. Other components, including the batteries, are mounted to the internal support composite I-beams, which are constructed with high conductivity carbon fiber. A main composite thermal strap links other components to the I-beams.

While this rover design is effective for regulating component temperatures during the hot lunar day, analysis has

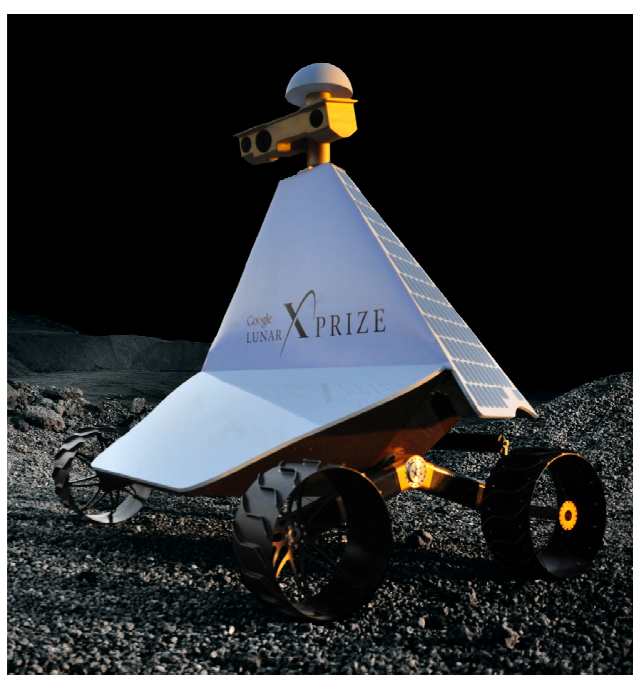

Figure 2.-Asymmetric rover for operation during the heat of the lunar equatorial day.

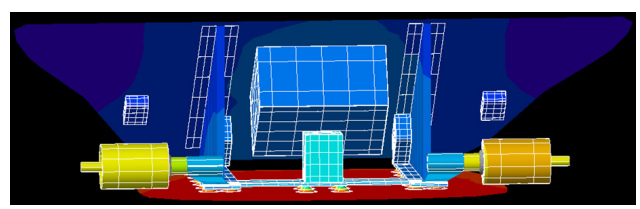

Figure 3.-Interior view of rover. Electronic components (blue boxes) are mounted directly on the radiator (top, in blue) or thermally sinked to the radiator through a thermal strap and thermally conductive I-beams. Components are insulated from the chassis floor (red) using MLI and isolation cones.

shown that it also loses heat quickly at sundown. Heaters are mounted on rover internal components to keep them warm during the flight to the Moon. If the rover were to sit unprotected on the lunar surface, running heaters through the length of the lunar night, it would need to carry more than its own mass in batteries (Ref. 1).

\section{B. Wadi Configuration}

The wadi in this analysis is constructed from fused lunar regolith. It is $0.5 \mathrm{~m}$ deep with an exposed surface area of $2.25 \mathrm{~m}^{2}$. The wadi is assumed to have the thermal properties of basalt, and to be embedded in lunar regolith such that only the top face is exposed. Table 1 shows the thickness and material properties of the wadi and the surrounding regolith.

TABLE 1.-THERMAL PROPERTIES OF WADI AND SURROUNDING REGOLITH

\begin{tabular}{|l|c|c|c|c|c|}
\hline & $\begin{array}{c}\text { Thickness, } \\
\mathrm{m}\end{array}$ & $\begin{array}{c}\text { Density, } \\
\mathrm{kg} / \mathrm{m}^{3}\end{array}$ & $\begin{array}{c}\text { Thermal conductivity, } \\
\mathrm{W} /(\mathrm{m} \mathrm{K})\end{array}$ & $\begin{array}{c}\text { Specific heat, } \\
\mathrm{J} /(\mathrm{kg} \mathrm{K})\end{array}$ & Emissivity \\
\hline Wadi (basalt) & 0.5 & 3000 & 2.1 & 800 & 0.9 \\
\hline Regolith & 0.2 & 1800 & 0.01 & 840 & 0.9 \\
\hline Shield & 0.005 & 1400 & 0.07 & 1000 & Varied \\
\hline
\end{tabular}

\footnotetext{
${ }^{2}$ This rover was developed at Carnegie Mellon University.
} 
The nominal wadi configuration includes a heat-loss-limiting shield that covers the wadi and rover, although a scenario without a heat-loss-limiting shield is also examined. The shield is rectangular for this analysis, although other shield shapes, such as a hemisphere or a pyramid, are also possible.

\section{3D Modeling}

The 3D model of the rover and wadi is built in Thermal Desktop (Ref. 7). The rover model is an updated version of the model used in previous work (Ref. 1). The total rover mass is $70 \mathrm{~kg}$. Figure 4 shows the approximate external surface areas and masses of rover components. The solar array assembly, radiator and chassis are modeled as composite panels with carbon fiber face sheets and aluminum honeycomb core. The dust cover, which connects the solar panels to the radiator, is a lightweight non-structural surface. Rover electronics are modeled as boxes for components, such as the computer, radio transceiver, and batteries. In reporting results, the electronics box (E-box) temperature is reported at the computer, which is mounted on the underside of the radiator. For this analysis, the rover temperature at the start of the lunar night is assumed to be a constant $300 \mathrm{~K}$. Conduction between the rover components is modeled, but conduction between the rover and the wadi is not modeled. This roverwadi conduction is not expected to be significant, since the area of contact between the wheels and the wadi surface is small and the contact pressure exerted by the $70 \mathrm{~kg}$ rover under lunar gravity is low.

The wadi in the 3D model is $1.5 \mathrm{~m}^{2}$ and $0.5 \mathrm{~m}$ in depth. A $0.2 \mathrm{~m}$ layer of regolith is modeled underneath the wadi. The regolith on the sides of the wadi is not modeled - instead it is assumed that there is no heat flow through the wadi sides. This assumption is based on previous analysis showing that results for a $3 \mathrm{D}$ wadi are very similar to results for a 1D wadi (Ref. 6). Figure 5 shows three different views of the rover on the wadi. The wadi temperature at the beginning of the lunar night is set based on 1D results for the wadi temperature versus depth after running for several day-night cycles to reach a periodic equilibrium. This temperature varies from $325 \mathrm{~K}$ at the bottom of the wadi to $287 \mathrm{~K}$ at the surface.

The shield in the 3D model has a top panel that is 1.5 by $1.5 \mathrm{~m}$ and four side panels that are 1.5 by $1.54 \mathrm{~m}$ (see Fig. 6). For case 1 with no shield, the shield is removed from the model and the rover and wadi can radiate to free space and to the lunar surface. For case 2, the shield emissivity is 0.3 , and for case 3 , it is 0.03 . The initial temperature of the shield, when present, is set to a constant $300 \mathrm{~K}$.

\section{A. 2D Modeling}

In the $2 \mathrm{D}$ model, we assume that the wadi is $2.25 \mathrm{~m}$ long and $0.5 \mathrm{~m}$ deep. The wadi is unbounded in the third dimension. For $1 \mathrm{~m}$ in this dimension, the wadi would have the same surface area $\left(2.25 \mathrm{~m}^{2}\right)$ as that used in the 3D model. To initialize the wadi temperature, we determine its temperature distribution (starting from a uniform temperature of $100 \mathrm{~K}$ ) at the end of daytime in the 4th lunar diurnal cycle. In this calculation, the solar flux impinging on the wadi surface during daytime is assumed to be sinusoidal in time, with a peak flux of $1300 \mathrm{~W} / \mathrm{m}^{2}$, and a vanishing flux during the night. During the lunar day

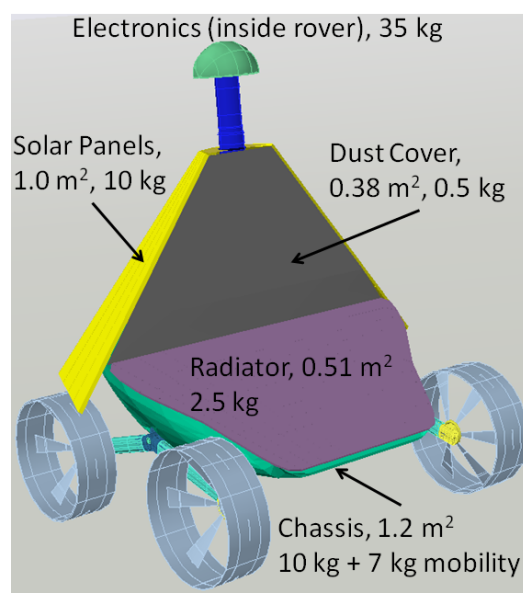

Figure 4.-3D rover thermal model, showing approximate external surface areas and masses of components.

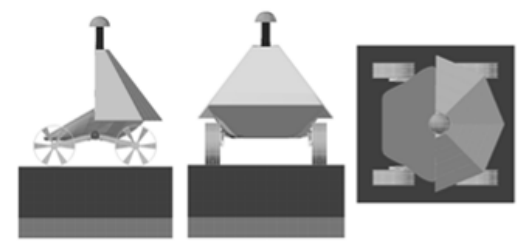

Figure 5.-3D model of rover on wadi.

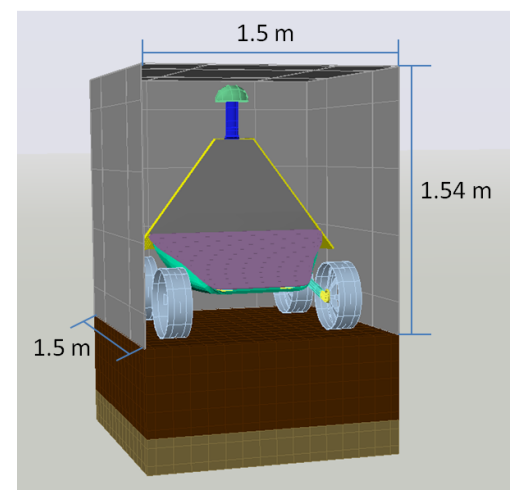

Figure $6 .-3 \mathrm{D}$ rover and wadi with shield (fifth face of shield not shown). 
and at night, the wadi surface loses heat by radiation to free space. The interaction of the rover and the wadi is then computed during the lunar night in the 4th cycle. In many cases, a radiation shield is also incorporated in the model at night in the 4th cycle to protect the rover and the wadi. The computations were performed using the COMSOL (Ref. 8) software.

The rover is assumed to arrive at the wadi at the beginning of the lunar night with a uniform temperature of $300 \mathrm{~K}$. In 3D, rover geometry is complicated, as many details of the hardware are incorporated in the model. The 2D model, however, simplifies the geometrical details, and only includes essential components required to faithfully predict thermal behavior. It should be noted that the 2D model is not a simple vertical cross-section of the rover $3 \mathrm{D}$ structure and care must be given to represent the actual 3D structure in 2D with an objective to capture the thermal interactions

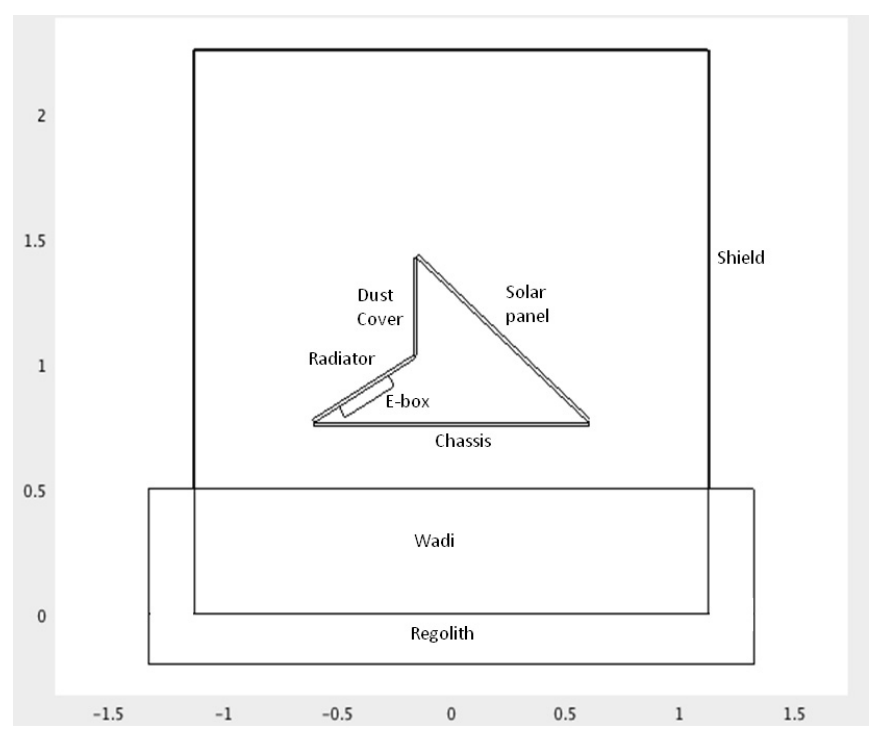

Figure 7.-2D model of rover on wadi. realistically. Figure 7 shows a schematic drawing of the 2D model of the wadi (and a portion of the surrounding regolith included in the computations), the various rover components, and a radiation shield that encloses the rover and the wadi. The rover components we include are (1) solar panel, (2) radiator, (3) chassis, (4) dust cover, and (5) E-box. The dimensions of these components and their thermal properties are summarized in Table 2. The radiator and the solar panel are at an angle with respect to the chassis so that their outer surfaces have a direct view of space for purposes of heat rejection by radiation. In the $2 \mathrm{D}$ model, the radiator and solar panel angles from the chassis are approximately $31^{\circ}$ and $40^{\circ}$, respectively. The geometrical lengths are chosen so that for a $1 \mathrm{~m}$ width in the third dimension in the $2 \mathrm{D}$ model, the areas of the components (other than the E-box) matched those from the 3D model. The E-box size is 0.25 by $0.05 \mathrm{~m}$. It has the thermal properties of aluminum. The thickness of the rest of the components is $0.015 \mathrm{~m}$. The effective density and specific heat of the chassis, radiator and solar panel are chosen to be $600 \mathrm{~kg} / \mathrm{m}^{3}$ and $900 \mathrm{~J} /(\mathrm{kg} \mathrm{K})$, and that of the dust cover is $5.5 \mathrm{~kg} / \mathrm{m}^{3}$ and $200 \mathrm{~J} /(\mathrm{kg} \mathrm{K})$. With these choices and for $1 \mathrm{~m}$ widths in the third dimension, the component masses are reasonably close to their masses in the $3 \mathrm{D}$ model and the total rover mass is $58.2 \mathrm{~kg}$.

In 3D, the rover rests on the wadi on its wheels as shown in Figure 4. To model the wheels in 2D, their widths would have to be extended in the third dimension, as in the case of the components. It is our assessment, however, that such a 2D model of the wheels would prevent the proper radiative exchange between the wadi, rover and the surroundings as the 2D wheels would artificially block a significant fraction of the radiant energy loss from the wadi. Since the overall goal is to capture the thermal interactions faithfully, our 2D model neglects the wheels. The chassis still sits $25 \mathrm{~cm}$ above the wadi surface, as in the 3D model.

It is necessary to protect the rover and wadi by a radiation shield that fully encloses them, so that radiative heat losses during the lunar night are reduced as much as possible. In 3D the surface area of the shield can be large (the shield chosen has a surface area almost 4 times the rover surface area). The 2D model also incorporates a radiation shield. Matching the shield area in the 2D model, however, renders the shield to be either very tall or very long, and the interpretations of 3Dto-2D comparisons might be ambiguous. We therefore chose the shield dimensions in $2 \mathrm{D}$ with reasonable resemblances to the shield height and length in 3D but yielding half the surface area of that in 3D. To compensate for the radiative power, we increase the shield emissivity to be twice that in the 3D model. Thus, the product of the emissivity and surface area $(\varepsilon A)$ for the shield is matched between the $2 \mathrm{D}$ and $3 \mathrm{D}$ models. While the procedure does not make the radiative power in the two cases exactly the same, we show by a simple analysis below that the approximation is fairly good.

Let the rover and the shield be approximated as lumped masses with surface area $A_{r}$ and $A_{s}$, and emissivity $\varepsilon_{r}$ and $\varepsilon_{s}$, respectively. Let $T_{r}$ and $T_{s}$ denote their temperatures. The shield protects the rover from radiative loss to free space, which is assumed to be a black body at essentially $0 \mathrm{~K}$. In the limit that the thermal masses of the rover and shield are negligible, the radiative power from the rover to the shield equals that from the shield to free space. This yields

$$
T_{s}^{4}=\frac{\frac{A_{r}}{\varepsilon_{s} A_{s}} T_{r}^{4}}{\frac{1}{\varepsilon_{r}}+\frac{2 A_{r}}{\varepsilon_{s} A_{s}}-\frac{A_{r}}{A_{s}}}
$$


TABLE 2.-2D MODEL DIMENSIONS AND MATERIAL PROPERTIES

\begin{tabular}{|l|c|c|c|c|c|}
\hline Name & $\begin{array}{c}\text { Dimensions, } \\
\mathrm{m}\end{array}$ & $\begin{array}{c}\text { Density, } \\
\mathrm{kg} / \mathrm{m}^{3}\end{array}$ & $\begin{array}{c}\text { Thermal } \\
\text { conductivity, } \\
\mathrm{W} /(\mathrm{m} \mathrm{K})\end{array}$ & $\begin{array}{c}\text { Specific heat, } \\
\mathrm{J} /(\mathrm{kg} \mathrm{K})\end{array}$ & Emissivity \\
\hline Chassis & 1.2 by 0.015 & 600 & 1 & 900 & 0.9 out \\
& 0.51 by 0.015 & 600 & 1 & 9 & 0.025 in \\
\hline $\begin{array}{l}\text { Radiator } \\
\text { chassis })\end{array}$ & & & & 00 & .9 \\
\hline E-box & 0.25 by 0.05 & 2700 & 200 & 900 & 0.9 \\
\hline $\begin{array}{l}\text { Solar panel }(40.2 \\
\text { deg w.r.t. chassis })\end{array}$ & 1 by 0.015 & 600 & 1 & 900 & 0.86 out \\
\hline Dust cover & 0.38 by 0.015 & 5.5 & 0.16 & 200 & 0.025 in \\
\hline
\end{tabular}

For fixed $T_{r}, \varepsilon_{r}, A_{r}$ and $\varepsilon_{s} A_{s}$, the shield temperature $T_{s}$ can be calculated for a given shield area $A_{s}$. Calculations show that in the parametric range of interest (i.e., $0.5<\varepsilon_{r}<1$ and $\left.A_{r} / A_{s} \sim 0.3\right), \Delta T_{s} / T_{s}=1-\left[T_{s}\left(0.5 A_{s}\right)\right] /\left[T_{s}\left(A_{s}\right)\right]$ is typically negative with magnitude less than 3 percent for $\varepsilon_{s}<0.5$, and less than 1 percent for $\varepsilon_{s}<0.1$. Thus matching the product $\varepsilon A$ for the shield in the $2 \mathrm{D}$ model can be anticipated to yield fairly accurate results for the temperature and the radiative power.

The 2D shield is $2.25 \mathrm{~m}$ long and $1.75 \mathrm{~m}$ high, with a thickness of $5 \mathrm{~mm}$. Aluminized Mylar is a good candidate material for the shield. We assume that the shield has a density of $1400 \mathrm{~kg} / \mathrm{m}^{3}$, thermal conductivity of $0.07 \mathrm{~W} /$ $(\mathrm{m} \mathrm{K})$ and specific heat of $1000 \mathrm{~J} /(\mathrm{kg} \mathrm{K})$. Its emissivity is varied in the range of 0.06 to 0.6 . Within the enclosure, the inner surface of the shield, the various rover surfaces and the wadi surface are in coupled radiative heat exchange. In the 2D model, we assume that the outer surface of the shield radiates to free space at a temperature of $4 \mathrm{~K}$. To model the absence of a shield, we set the temperature of the shield to the environment temperature $(4 \mathrm{~K})$ in the 2D model. No radiative exchange between the shield and the external planetary surface is considered. Such an interaction would tend to reduce the net radiative loss from the shield to the environment. Therefore our results represent a worst case scenario. In the simulations, the shield has an initial temperature of $300 \mathrm{~K}$ at the start of the lunar night during the 4th diurnal cycle. Note that the calculations to initialize the wadi temperature distribution at this time did not consider the presence of a shield during the night in the first three diurnal cycles. Our previous calculations (Ref. 9) (where an effective wadi emissivity was used during the night to model the presence of a radiation shield) show that the wadi temperature at sunset is quite insensitive to the presence or absence of a nighttime radiation shield.

\section{A. Results}

The variation with time of the temperature of the wadi surface and the E-box are shown in Figure 8. The unprotected rover gets very cold and E-box has a temperature of $127 \mathrm{~K}$ at the end of the night. Therefore an unprotected rover cannot operate through the lunar night. The minimum temperature of the wadi surface is $217 \mathrm{~K}$ in the $2 \mathrm{D}$ results and $197 \mathrm{~K}$ in the $3 \mathrm{D}$ results. Figure 9 shows $2 \mathrm{D}$ and $3 \mathrm{D}$ results for the temperature distributions of the rover and wadi at the end of the lunar night.

The behaviors of the temperature of the wadi surface, E-box and shield over time for case 2 are shown in Figure 10. The 3D and 2D temperature distributions at the end of the lunar night are shown in Figure 11. The wadi surface and E-box are warmer by approximately 20 and $50 \mathrm{~K}$, respectively, in the presence of the shield. Note that the $2 \mathrm{D}$ results are for a shield with an emissivity of 0.6 and the corresponding $3 \mathrm{D}$ results are for a shield emissivity of 0.3 . Since the minimum temperature for rover operation is approximately $243 \mathrm{~K}$, the shield emissivity must be lower to further reduce radiative heat loss to the environment.

When the emissivity of the shield is reduced $\left(\varepsilon_{s}=0.06\right.$ for $2 \mathrm{D}$ and 0.03 for $\left.3 \mathrm{D}\right)$, we see from Figure 12 that the E-box temperature during the lunar night is sufficiently warm (minimum temperature is $266 \mathrm{~K}$ for $2 \mathrm{D}$ and $248 \mathrm{~K}$ for $3 \mathrm{D}$ ). Figure 13 shows the $2 \mathrm{D}$ and 3D temperature distributions at the end of the night. Compared with the unshielded case, the wadi and E-box temperatures at the end of nighttime are significantly warmer, (64 to $80 \mathrm{~K}$ warmer for the wadi and 121 to $139 \mathrm{~K}$ warmer for the E-Box). Therefore, a radiation shield that adequately prevents heat loss from the rover and the wadi appears to be essential for the nighttime operation of the rover. A summary of the 2D and 3D results for end of night temperatures for all three cases is presented in Table 3. 


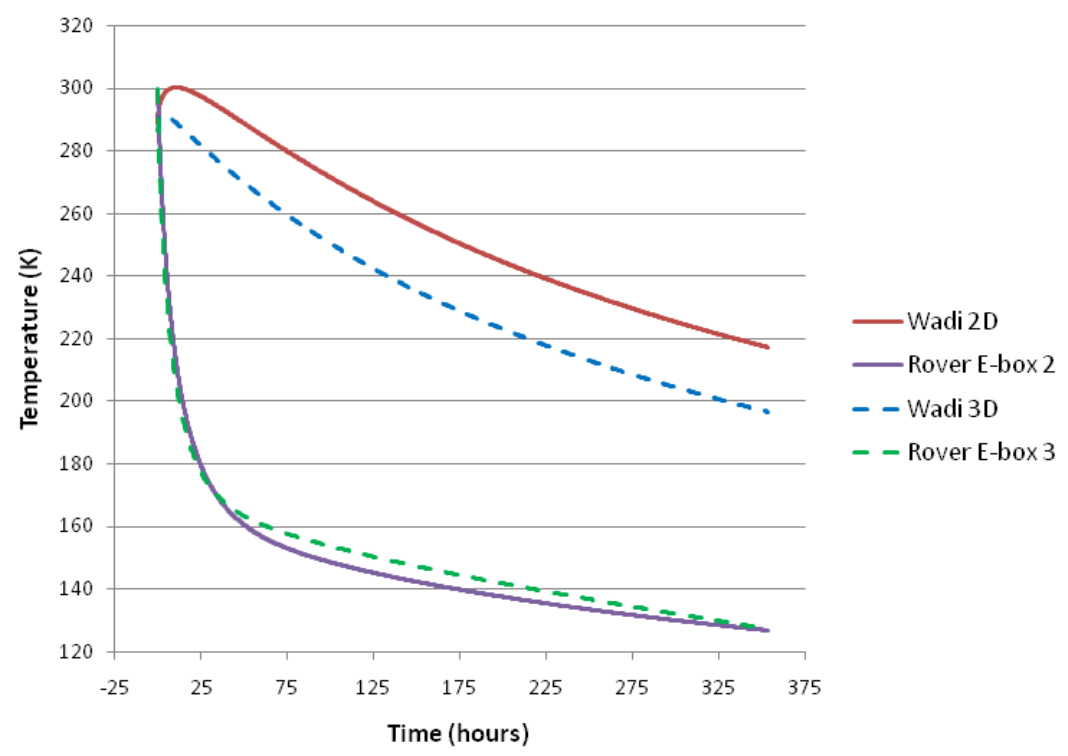

Figure 8.-Temperature versus time during lunar night for rover on wadi with no shield (case 1).
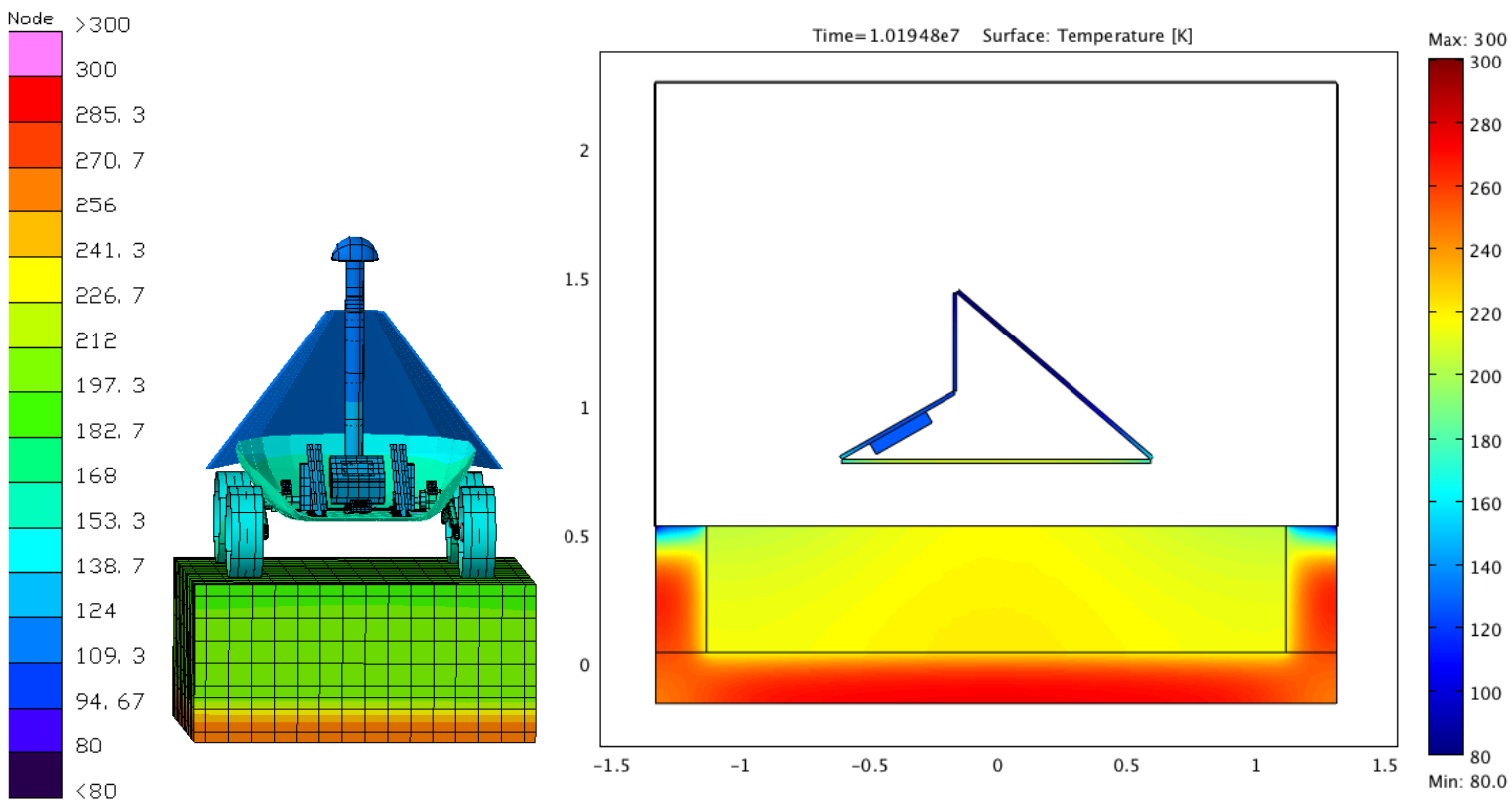

Figure 9.-3D (left) and 2D (right) temperature distribution at end of lunar night for wadi and rover with no shield (case 1). 


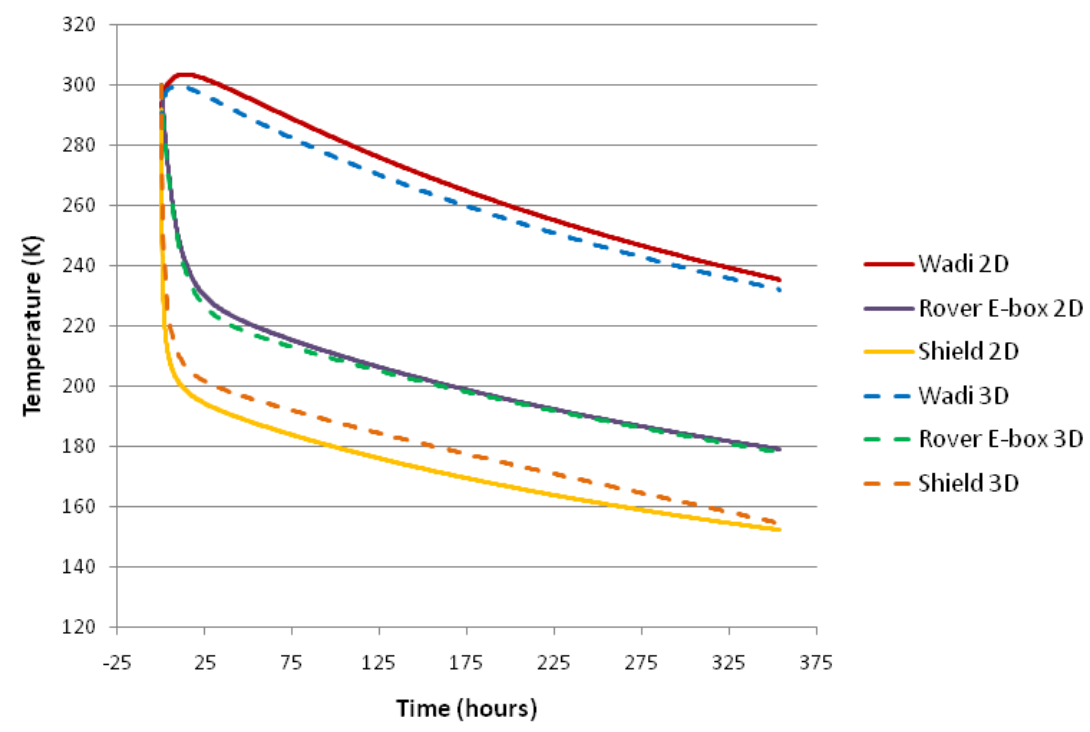

Figure 10.-3D and 2D results for rover on wadi with shield (case 2).
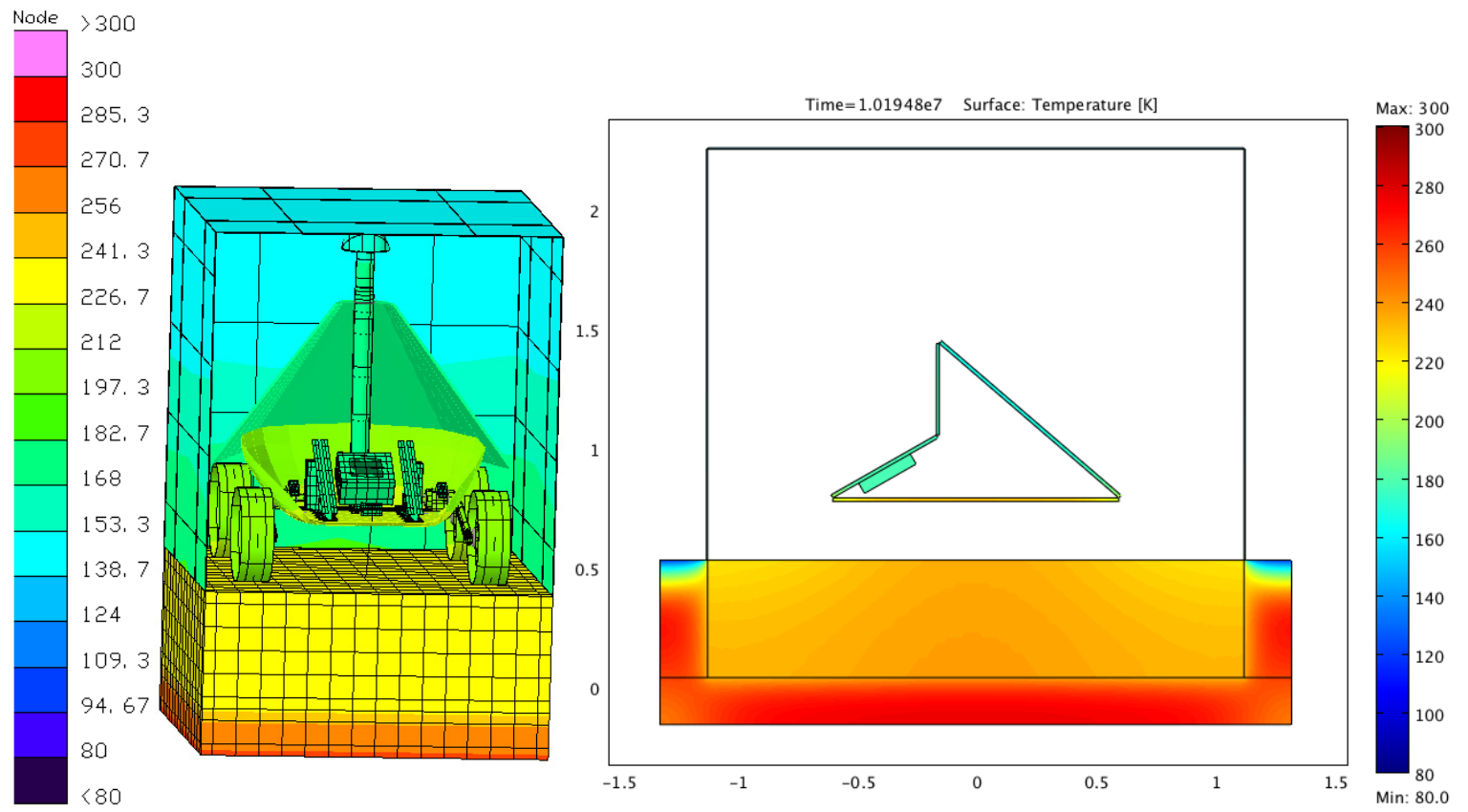

Figure 11.-3D (left) and 2D (right) temperature distribution at end of lunar night for wadi and rover with shield (case 2). 


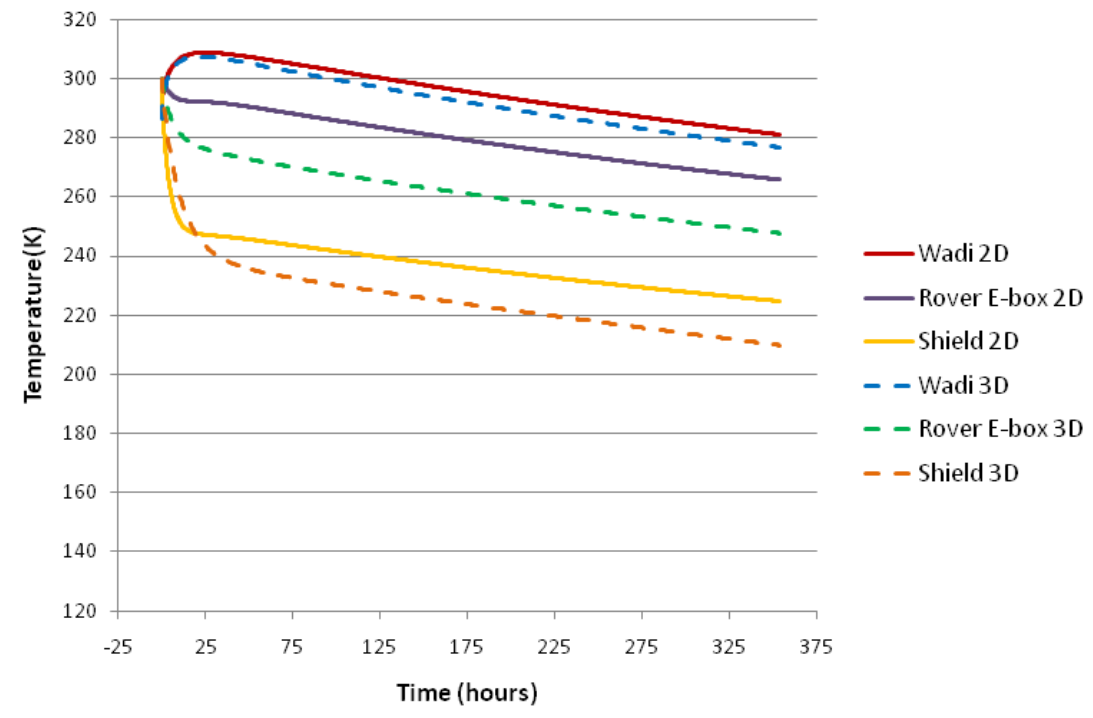

Figure 12.-3D and 2D results for rover on wadi with low emissivity shield (case 3).
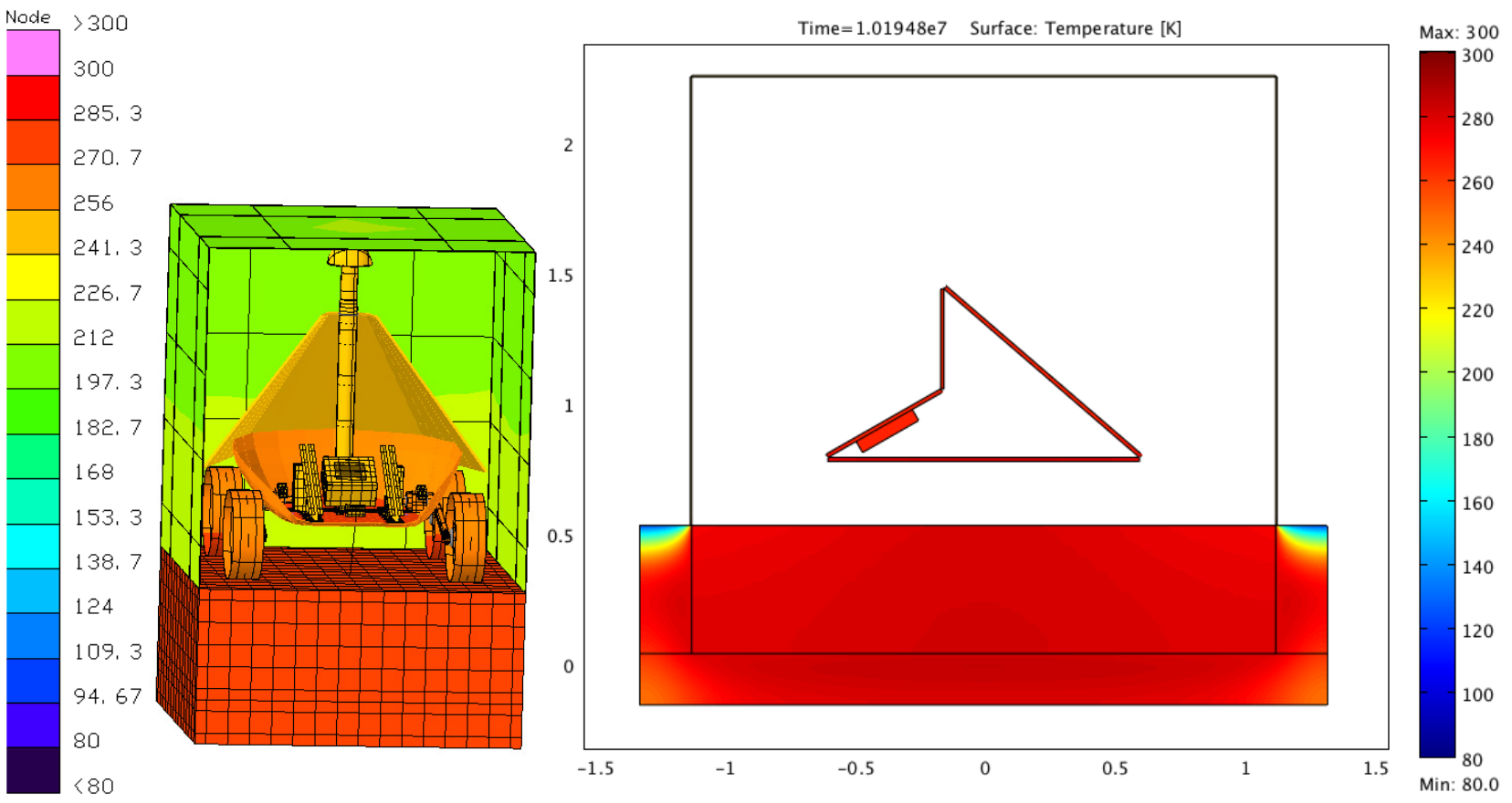

Figure 13.-3D (left) and 2D (right) temperature distribution at end of lunar night for wadi and rover with low emissivity shield (case 3). 
TABLE 3.-COMPARISON OF 2D AND 3D RESULTS FOR END OF NIGHT

\begin{tabular}{|l|c|c|c|c|c|c|}
\hline \multirow{2}{*}{$\begin{array}{l}\text { Shield } \\
\text { emissivity }\end{array}$} & \multicolumn{3}{|c|}{ 2D } & \multicolumn{3}{|c|}{ 3D } \\
\cline { 2 - 7 } & Wadi & E-box & Shield & Wadi & E-box & Shield \\
\hline No shield & $217 \mathrm{~K}$ & $127 \mathrm{~K}$ & ------ & $197 \mathrm{~K}$ & $127 \mathrm{~K}$ & ------- \\
\hline $\begin{array}{l}0.6(2 \mathrm{D}) \\
0.3(3 \mathrm{D})\end{array}$ & $235 \mathrm{~K}$ & $179 \mathrm{~K}$ & $152 \mathrm{~K}$ & $232 \mathrm{~K}$ & $178 \mathrm{~K}$ & $154 \mathrm{~K}$ \\
\hline $\begin{array}{l}0.06(2 \mathrm{D}) \\
0.03(3 \mathrm{D})\end{array}$ & $281 \mathrm{~K}$ & $266 \mathrm{~K}$ & $225 \mathrm{~K}$ & $277 \mathrm{~K}$ & $248 \mathrm{~K}$ & $210 \mathrm{~K}$ \\
\hline
\end{tabular}

\section{A. Discussion}

This analysis has shown good correspondence of 2D and 3D thermal models of wadi and rover. Consistent trends are apparent in both models. Both models show that a wadi with a low emissivity shield can keep a rover's electronics above $243 \mathrm{~K}$ throughout the lunar night. This is a viable operating temperature for electronics. A 2D rover model that corresponds to the 3D geometry must be constructed carefully. Surface areas, angles and view factors matter, as do the component masses for realistic widths in the third dimension. A generic rectangular boxshaped 2D model with 2D wheels resting on the wadi surface that was initially used did not match as well with the results from the $3 \mathrm{D}$ model. This is not surprising, since the angled radiator in the $3 \mathrm{D}$ rover is designed to have less of a view factor to the ground plane than a vertical panel, and the wheels in 2D create an artificial radiative barrier that does not exist in 3D.

Some changes can be made easily with the $3 \mathrm{D}$ model such as surface coatings, insulation, and heating of individual components. The heating of individual components, as discussed in Section I, can only be done effectively with the more detailed 3D model. For other changes, such as geometric modifications, it is significantly easier to modify the 2D model. This suggests a process by which a $2 \mathrm{D}$ model can be used to readily evaluate prospects, and then more detailed 3D models can be built to rigorously examine the contenders.

\section{Analysis of Wadi Amenities}

If a rover will spend each lunar night (half its time) on a wadi, it makes sense to examine what other utility the wadi might offer. A natural choice is electrical power. A rover cannot generate power from solar panels during the night, and the battery power needed to operate continuously through the night is even greater than that needed to keep an unprotected rover warm. A wadi creates a temperature differential between its mass and the surrounding terrain, so heat powered electricity generation was considered, but this temperature differential is much smaller than that generally seen in Stirling engine systems. Battery power, however, is a reasonable option. Because the wadi is stationary, adding a large battery mass does not pose the problems that would occur if the same mass were added to a mobile system. A wadi battery could be charged during the day from solar panels mounted near the wadi. As with the battery, solar panels for a stationary wadi can be much larger than those for a mobile rover. Electrical interface between a rover and a wadi battery might be accomplished using contact plates on the surface of the wadi, or a more complicated surface mounted plug could be designed. Another option is to use an inductive coupling or other noncontact method of power transmission. In any case, this interface must be robust to repeated connection/ disconnection cycles. Automated docking for power recharge is a demonstrated capability in terrestrial robotics.

In $2 \mathrm{D}$ analysis, we examine where a battery might be placed with respect to the wadi to avoid exceeding both the minimum and maximum operating temperatures. In 3D analysis, we explore a concept for using a wadi battery to heat rover components, so that a rover could be brought up to operating temperatures quickly, even with a lower shield emissivity. 


\section{A. 2D Wadi Battery Analysis}

\section{Method}

In order to model the behavior of a battery buried in the wadi, we first consider the heat-up of the battery due to resistive heating while it is being charged. A typical charging current is $3 \mathrm{~A}$, and a typical cell resistance is $0.01 \Omega$. Thus a battery pack with 36 cells in series with a total mass $M=4 \mathrm{~kg}$ has a joule heating rate of $P=3.24 \mathrm{~W}$. Lab tests indicate that $90 \mathrm{~min}$ is sufficient for charging the battery. For a battery that is regarded as a lumped mass isolated from the surroundings, the temperature rise may be calculated as

$$
\Delta T=P t /\left(M C_{p}\right)
$$

where $C_{p}$ is the specific heat of the battery, which is taken to be $800 \mathrm{~J} /(\mathrm{kg} \mathrm{K})$. The temperature rise of the battery is obtained to be $\Delta T=5.5 \mathrm{C}$. Due to the heat loss to the wadi surrounding the battery, the temperature rise will be less than that estimated.

Since the diurnal temperature swing on the lunar surface is much larger than the temperature rise due to joule heating of the battery, the temperature of the battery will be controlled by its energy exchange with the wadi. The lunar surface diurnal temperature swing, however, is much too large for survival of the battery. In order to mitigate the temperature swing, we investigated the placement of the battery at various locations within the wadi and the regolith adjacent to it.

\section{Results}

We have calculated the temperature distribution at selected locations within the wadi and the regolith adjacent to it using a $2 \mathrm{D}$ model. The wadi is assumed to be $1 \mathrm{~m}$ long and $0.5 \mathrm{~m}$ deep. It is assumed to be of infinite extent in the third dimension. The peak solar flux is taken to be $1300 \mathrm{~W} / \mathrm{m}^{2}$. We assume that a daytime solar reflector is available to collect sunlight throughout the lunar day and illuminate the wadi surface such that the light is perpendicular to it. During the lunar night, we assume that the wadi is protected by a radiation shield such that the effective emissivity of the wadi surface is reduced to 0.25 from its unshielded value of 0.9 .

Figure 14 shows the temperature variation with time at various locations within the wadi and the surrounding regolith. The results are shown in the sixth diurnal cycle. For an initial condition, the temperature of the wadi has been assumed to be $100 \mathrm{~K}$ everywhere. Conditions close to a periodic steady-state are achieved in six cycles. It is seen that the temperature swing in the wadi or at the surface of the regolith are in excess of $100 \mathrm{~K}$, and are not suitable for placement of the battery. An ideal location for the battery appears to be $20 \mathrm{~cm}$ away from the edge of the

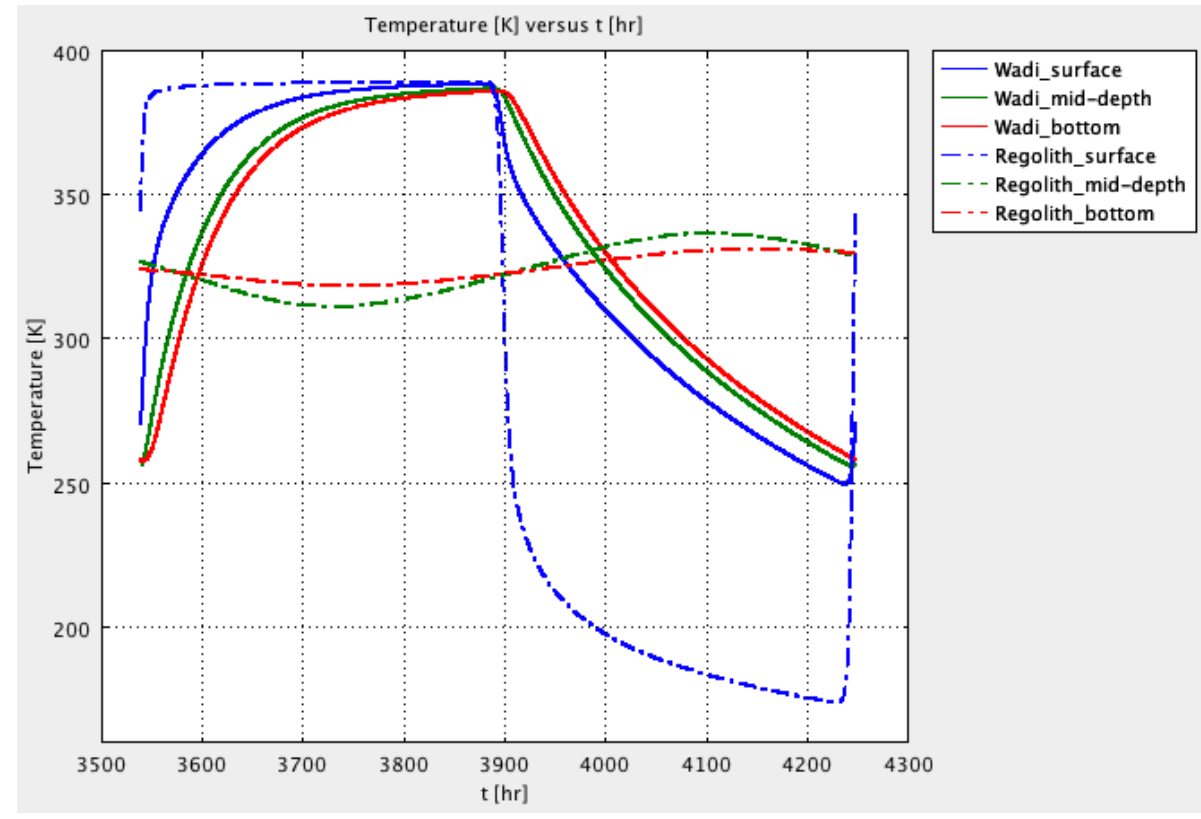

Figure 14.-Results for wadi temperature by depth. 
basalt wadi into the regolith, and a depth of $25 \mathrm{~cm}$ below the surface (corresponding to the Regolith_mid-depth curve in the figure). The temperature here is approximately in the range 310 to $335 \mathrm{~K}$, and is anticipated to be compatible with the battery chemistry. While the results shown in the figure at the regolith mid-depth location is the regolith temperature in the absence of a battery, calculations show that a battery ( 5 by $5 \mathrm{~cm}$; without joule heating) placed there practically achieves the same temperature.

\section{B. 3D Heating Analysis}

\section{Method}

For the equatorial rover configuration examined in this work, electronic components have heaters for use during transit to the Moon. These heaters could also be used to bring rover components back up to operating temperatures before lunar dawn in order to take measurements at the lunar terminator after a night spent on a wadi with a degraded shield. We assume that the heat power that can be applied to a component via resistive heating is dependent on the component surface area. Two watt-densities are examined 5 and $10 \mathrm{~W} / \mathrm{in}^{2}{ }^{2}(7750$ and $\left.15500 \mathrm{~W} / \mathrm{m}^{2}\right){ }^{3}$ Table 4 shows the heat power applied per component given these power densities and the component surface areas.

TABLE 4.-HEATER POWER

\begin{tabular}{|l|c|c|c|}
\hline \multicolumn{1}{|c|}{ Component } & $\begin{array}{c}\text { Surface area, } \\
\mathrm{m}^{2}\end{array}$ & Power at 10 W/in. & Power at 5 W/in. ${ }^{2}$ \\
\hline Battery $(\mathrm{x} 4)$ & 0.027342 & 424 & 212 \\
\hline Computer & 0.047633 & 738 & 369 \\
\hline Communications (x3) & 0.0044743 & 69 & 35 \\
\hline Motor control (x2) & 0.0031124 & 48 & 24 \\
\hline Total & & $\mathbf{2 7 3 8}$ & $\mathbf{1 3 6 9}$ \\
\hline
\end{tabular}

\section{Results}

Table 5 shows the time and battery capacity needed to warm rover components with two different heater-bus power levels.

TABLE 5.-TIME AND BATTERY CAPACITY TO BRING COMPONENTS WITHIN OPERATING TEMPERATURES

\begin{tabular}{|c|c|c|c|}
\hline $\begin{array}{c}\text { Total heater power, } \\
\mathrm{W}\end{array}$ & $\begin{array}{c}\text { Time to bring components above } \\
243 \mathrm{~K}, \\
\mathrm{~S}\end{array}$ & $\begin{array}{c}\text { Time to bring components above } \\
243 \mathrm{~K}, \\
\mathrm{hr}\end{array}$ & $\begin{array}{c}\text { Battery capacity } \\
\text { expended, } \\
\mathrm{W} \mathrm{hr}\end{array}$ \\
\hline 1369 & 1170 & 0.33 & 452 \\
\hline 2738 & 645 & 0.18 & 493 \\
\hline
\end{tabular}

\section{Discussion}

A battery buried at appropriate proximity to a wadi stays at a viable operating temperature throughout lunar night. Such a battery could provide power to a solar powered rover through the sunless night. It could also be used to actuate the wadi shield. This battery can be much heavier and more capable than that incorporated in a mobile rover. Solar panels could be mounted near the wadi to charge batteries during day.

\section{Conclusions}

A wadi with a shield can keep a rover within operating temperatures through the night, if a low enough emissivity shield is used. An emissivity of 0.03 is found to be sufficient to keep rover electronics above $-30{ }^{\circ} \mathrm{C}$. A large battery buried beside a wadi could be used to power a rover for operation through the night. If the wadi shield emissivity degrades, the rover may not stay within operating temperatures using wadi heat alone, but the presence of a wadi would still significantly reduce the battery power needed to heat the rover. The presence of a battery at a wadi solves the dual need of electrical power and heating for night operation of electronics on the lunar surface.

\footnotetext{
${ }^{3}$ A datasheet from Omega Engineering, Inc. offers three power densities for flexible kapton heaters: 10,5 , and $2.5 \mathrm{~W} /$ in. $^{2}$ (http://www.omega.com/Heaters/pdf/KHR_KHLV_KH.pdf)
} 


\section{References}

1. J. Thornton, W. Whittaker, H. Jones, M. Mackin and R. Barsa, "Thermal Strategies for Long Duration Mobile Lunar Surface Missions,” AIAA Aerospace Sciences Meeting, January 2010.

2. D. Wettergreen, B. Shamah, P. Tompkins, W. Whittaker, "Robotic Planetary Exploration by Sun-Synchronous Navigation," Proceedings of the 6th International Symposium on Artificial Intelligence, Robotics and Automation in Space (i-SAIRAS '01), June, 2001.

3. Paige, D.A., Foote, M.C., Greenhagen, B.T., Schofield, J.T., Calcutt, S., Vasavada, A.R., Preston, D.J., Taylor, F.W., Allen, C.C., Snook, K.J., Jakosky, B.M., Murray, B.C., Soderblom, L.A., Jau, B., Loring, S., Bulharowski J., Bowles, N.E., Thomas, I.R., Sullivan, M.T., Avis, C., De Jong, E.M., Hartford, W., McCleese, D.J. "The Lunar Reconnaissance Orbiter Diviner Lunar Radiometer Experiment," Space Science Reviews, 2010, vol. 150, no. $1-4$, pp. $125-160$.

4. Creel, R., "The Lunokhods - Russia's marvelous robotic rovers," Appendix 2 of Lunar and Planetary Rovers by Anthony Young, Praxis, 2007.

5. R. Balasubramaniam, R. Wegeng, S. Gokoglu, N. Suzuki, K. Sacksteder, "Analysis of Solar-Heated Thermal Wadis to Support Extended-Duration Lunar Exploration," AIAA Aerospace Sciences Meeting, January 2009.

6. R. Balasubramaniam, S. Gokoglu, K. Sacksteder, R. Wegeng and N. Suzuki, "An Extension of Analysis of Solar-Heated Thermal Wadis to Support Extended-Duration Lunar Exploration," AIAA Aerospace Sciences Meeting, January 2010.

7. Thermal Desktop, Software Package, Ver. 5.3, C\&R Technologies, Boulder, CO, 2010.

8. COMSOL Software Package, Ver. 3.5a, COMSOL Inc., Burlington, MA, 2010.

9. R. Balasubramaniam, S. Gokoglu, K. Sacksteder, R. Wegeng and N. Suzuki, "Analysis of Solar-Heated Thermal Wadis to Support Extended-Duration Lunar Exploration," J. Thermophysics and Heat Transfer, in press. 


\begin{tabular}{|c|c|c|c|c|c|}
\hline \multicolumn{5}{|c|}{ REPORT DOCUMENTATION PAGE } & $\begin{array}{c}\text { Form Approved } \\
\text { OMB No. 0704-0188 }\end{array}$ \\
\hline \multicolumn{6}{|c|}{$\begin{array}{l}\text { The public reporting burden for this collection of information is estimated to average } 1 \text { hour per response, including the time for reviewing instructions, searching existing data sources, gathering and maintaining the } \\
\text { data needed, and completeting and reviewing the collection of information. Send comments regarding this burden estimate or any other aspect of this collection of information, including suggestions for reducing this } \\
\text { burden, to Department of Defense, Washington Headquarters Services, Directorate for Information Operations and Reports (0704-0188), } 1215 \text { Jefferson Davis Highway, Suite } 1204 \text {, Arlington, VA } 22202-4302 \text {. } \\
\text { Respondents should be aware that notwithstanding any other provision of law, no person shall be subject to any penalty for failing to comply with a collection of information if it does not display a currently valid OMB } \\
\text { control number. } \\
\text { PLEASE DO NOT RETURN YOUR FORM TO THE ABOVE ADDRESS. }\end{array}$} \\
\hline \multicolumn{2}{|c|}{$\begin{array}{l}\text { 1. REPORT DATE (DD-MM-YYYY) } \\
01-03-2011\end{array}$} & \multicolumn{3}{|c|}{$\begin{array}{l}\text { 2. REPORT TYPE } \\
\text { Technical Memorandum }\end{array}$} & 3. DATES COVERED (From - To) \\
\hline \multirow{3}{*}{\multicolumn{5}{|c|}{$\begin{array}{l}\text { 4. TITLE AND SUBTITLE } \\
\text { Enabling Long-Duration Lunar Equatorial Operations With Thermal Wadi Infrastructure }\end{array}$}} & 5a. CONTRACT NUMBER \\
\hline & & & & & 5b. GRANT NUMBER \\
\hline & & & & & 5c. PROGRAM ELEMENT NUMBER \\
\hline \multirow{3}{*}{\multicolumn{5}{|c|}{$\begin{array}{l}\text { 6. AUTHOR(S) } \\
\text { Jones, Heather, L.; Thornton, John, P.; Balasubramaniam, Ramaswamy; Gokoglu, Suleyman, } \\
\text { A.; Sacksteder, Kurt, R.; Whittaker, William, L. }\end{array}$}} & 5d. PROJECT NUMBER \\
\hline & & & & & 5e. TASK NUMBER \\
\hline & & & & & $\begin{array}{l}\text { 5f. WORK UNIT NUMBER } \\
\text { WBS } 075585.01 .06 .01 .03 .03\end{array}$ \\
\hline \multicolumn{5}{|c|}{$\begin{array}{l}\text { 7. PERFORMING ORGANIZATION NAME(S) AND ADDRESS(ES) } \\
\text { National Aeronautics and Space Administration } \\
\text { John H. Glenn Research Center at Lewis Field } \\
\text { Cleveland, Ohio 44135-3191 }\end{array}$} & $\begin{array}{l}\text { 8. PERFORMING ORGANIZATION } \\
\text { REPORT NUMBER } \\
\text { E-17633 }\end{array}$ \\
\hline \multirow{2}{*}{\multicolumn{5}{|c|}{$\begin{array}{l}\text { 9. SPONSORING/MONITORING AGENCY NAME(S) AND ADDRESS(ES) } \\
\text { National Aeronautics and Space Administration } \\
\text { Washington, DC 20546-0001 }\end{array}$}} & $\begin{array}{l}\text { 10. SPONSORING/MONITOR'S } \\
\text { ACRONYM(S) } \\
\text { NASA }\end{array}$ \\
\hline & & & & & $\begin{array}{l}\text { 11. SPONSORING/MONITORING } \\
\text { REPORT NUMBER } \\
\text { NASA/TM-2011-216994 }\end{array}$ \\
\hline \multicolumn{6}{|c|}{$\begin{array}{l}\text { 12. DISTRIBUTION/AVAILABILITY STATEMENT } \\
\text { Unclassified-Unlimited } \\
\text { Subject Categories: } 29 \text { and } 34 \\
\text { Available electronically at http://www.sti.nasa.gov } \\
\text { This publication is available from the NASA Center for AeroSpace Information, 443-757-5802 }\end{array}$} \\
\hline \multicolumn{6}{|c|}{ 13. SUPPLEMENTARY NOTES } \\
\hline \multicolumn{6}{|c|}{$\begin{array}{l}\text { 14. ABSTRACT } \\
\text { Long duration missions on the Moon's equator must survive lunar nights. With } 350 \mathrm{hr} \text { of cryogenic temperatures, lunar nights present a } \\
\text { challenge to robotic survival. Insulation is imperfect, so it is not possible to passively contain enough heat to stay warm through the night. } \\
\text { Components that enable mobility, environmental sensing and solar power generation must be exposed, and they leak heat. Small, } \\
\text { lightweight rovers cannot store enough energy to warm components throughout the night without some external source of heat or power. } \\
\text { Thermal wadis, however, can act as external heat sources to keep robots warm through the lunar night. Electrical power can also be provided } \\
\text { to rovers during the night from batteries stored in the ground beside wadis. Buried batteries can be warmed by the wadi's heat. Results from } \\
\text { analysis of the interaction between a rover and a wadi are presented. A detailed three-dimensional (3D) thermal model and an easily } \\
\text { configurable two-dimensional (2D) thermal model are used for analysis. }\end{array}$} \\
\hline \multicolumn{6}{|c|}{$\begin{array}{l}\text { 15. SUBJECT TERMS } \\
\text { Lunar surface systems; Robotic exploration; Energy storage; Solar thermal heating; Lunar environment; Vision for Space Exploration; } \\
\text { Lunar architecture }\end{array}$} \\
\hline \multicolumn{3}{|c|}{ 16. SECURITY CLASSIFICATION OF: } & $\begin{array}{l}\text { 17. LIMITATION OF } \\
\text { ABSTRACT }\end{array}$ & $\begin{array}{l}\text { 18. NUMBER } \\
\text { OF }\end{array}$ & $\begin{array}{l}\text { 19a. NAME OF RESPONSIBLE PERSON } \\
\text { STI Help Desk (email:help@sti.nasa.gov) }\end{array}$ \\
\hline $\begin{array}{l}\text { a. REPORT } \\
\text { U }\end{array}$ & $\begin{array}{l}\text { b. ABSTRACT } \\
\text { U }\end{array}$ & $\begin{array}{l}\text { c. THIS } \\
\text { PAGE } \\
\text { U }\end{array}$ & UU & $\begin{array}{l}\text { PAGES } \\
19\end{array}$ & $\begin{array}{l}\text { 19b. TELEPHONE NUMBER (include area code) } \\
443-757-5802\end{array}$ \\
\hline
\end{tabular}



